\title{
Urbarinzation and the Challenge of Climate Change in Nigeria Cities: A Review.
}

\author{
${ }^{1}$ Enete Ifeanyi .C, ${ }^{2}$ Ayadiulo, R.U \\ ${ }^{I}$ Dept. Of Geography \& Meteorology, Nnnamdi Azikiwe University, Awka. \\ ${ }^{2}$ Dept. Of Geography, University of Nigeria, Nsukka.
}

\begin{abstract}
Climate Change is currently one of the most challenging global environmental issues facing our generation. This paper presents an analytical review of the interactions between urban centers and climate change. The paper has a focus on two main themes: the interaction between urban centers and the generation of GHGs and the consequences of climate change on urban centers. Global warming is created by such activities like combustion of fossil fuels and land use changes with wide ranging consequences to our urban centers. Although, Climate change is a global issue in its manifestations, global warming is deeply a local issue. It is based on this, that urban centers of different sizes play a major role in the climate change issues. Urban households, industries, and infrastructure are the key sources of greenhouse gases. Urban centers concentrate populations, economic activities and built environment, thus increasing their risk from floods, heat waves, drought and other climate and weather hazards that climate change is expected to aggravate. Aside these risks and vulnerabilities that climate change brings to urban areas, these same urban centers also play pivotal roles in the mitigation and adaptation efforts. Urban centers are hubs of development, sources of innovation and policy responses to reduce greenhouse gases needed to adapt to climate change. It is this combination within urban centers of increased vulnerabilities along with increased opportunities that can generate important synergies for developing new technologies for adaptation and mitigation strategies. This paper contributes to the wealth of knowledge already existing on climate change by specifically looking at the impact of climate change on Nigeria cities. A comprehensive review of literature using electronic and non-electronic databases formed the methodology.
\end{abstract}

Key words: Climate change, Urban centers, mitigation, adaptation, vulnerabilities, Urbanization

\section{Introduction:}

Today the world faces a very dangerous threat, fuelled by two powerful human- induced forces: Urbanization and climate change. The effects of Urbanization and climate change are converging in dangerous ways which threaten to have unprecedented negative impacts upon quality of life, economic and social stability. Climate change is an issue created by human induced driving forces such as the combustion of fossil fuel. The range of effects has included a warming of sea surface temperature (SST) that has given us warning signs like the collapse of the ice shelves such as in Antarctica, propelling a dangerous sea level rise that now threaten may Urban Centers along the coasts (Larsen, 1995, Larsen, 2012).

The coastal cities of Nigeria is an embodiment of vulnerabilities; inundation and displacement of low lands and wetlands; coastal erosion, intensification of coastal storm flooding, increase in salinity of estuaries, saltwater intrusion into fresh water aquifers and degradation of water quality; change of sediment deposition patterns (IPCC,1991). About 20 percent of Nigeria's population estimated at about 111.7 million in 1995 lives in cities along the $853 \mathrm{~km}$ coastline, of which Lagos is the most important (Hughes and Hughes, 1992; Awosika et al; 1992).

Urban areas occupy only $2.8 \%$ of the earth's surface; yet more than $50 \%$ of the world's population inhabits urban areas (World Bank 2009). Rapid urbanization is occurring largely in developing countries where a massive demographic shift has enormous implications in terms of poverty, natural resources and the environment. By 2050, the Urban population of the developing world will be 5.2 billion (UN, 2010). Levels of urbanization are expected to rise, with the least urbanized regions of Asia and Africa transforming from largely rural societies to predominantly urban regions by 2050 (UN, 2010).

Urban household, industries and infrastructures within them are the very sources of greenhouse gases. Urban areas concentrate populations, economic activities and built environment thus increasing their risk from floods, heat waves and other climate and weather hazards that climate change is expected to aggravate. Many weather-related risks which already have an urban face will be exacerbated as climate change progress and hazards such as sea-level rise, salt-water intrusion and more intense storms become day-to-day realities for the poor and vulnerable populations that inhabit many of the most hazardous areas of our urban centers. But beyond the obvious threats posed by the convergence of the effects of Urbanization and climate change, these same urban centers may play a pivotal role in our mitigation and adaptation effort as well. Urban areas, with their high 
concentration of population, industries and infrastructure, are likely to face the most severe impacts of climate change. The same urban centers are hubs of development, sources of innovations and policy responses that can be catalyzed to promote reductions in greenhouse gas emissions. The economies of scale, as well as proximity and concentration of enterprise in cities, make it cheaper and easier to take the actions and provide the services necessary to minimize both emissions and climate hazards (Dodman, 2009; Romero Lankao et al., 2008, 2009).

It is this combination, within urban areas of increased vulnerabilities along with increased opportunities that can incubate important synergies and mitigation strategies; and give our urban centers the power and possibility to become the loci of change that we need in order to solve this global problem. It is crucial to recognize that cities and urban residents are not just victims of climate change but also part of the problem. If cities are part of the problem, that means they must also be part of any solution. The purpose of this study, therefore, is to identify the main issues of concern as they relate to urban areas and climate change in Nigeria. These attempts will unmask the vulnerable sectors and sets of opportunities the convergence of the effects of urbanization and climate change holds for Nigeria Cities.

\subsection{Methodology}

Literatures were identified for review through a comprehensive search by using electronic and nonelectronic databases. Related published literature and documents were searched in a systematic way using a range of key words relating to climate change impacts and urbanization issues. Also, the study employed descriptive statistics to analyze greenhouse gas emissions by different sectors.

\subsection{The Climate System}

The climate of the earth is affected by several factors including: the incoming energy from the sun, the outgoing energy leaving the Earth, and the exchange of energy among oceans, land, atmosphere, ice and living organisms. The structure and dynamics within both the carbon cycle and atmosphere can be equally responsible for alterations in climate. Within the atmosphere, incoming solar radiation and outgoing infrared radiation are affected by some gases and aerosols. Most aerosols have some cooling effect. The amount of greenhouse gas present in the Earth's atmosphere before human beings began the large-scale emission of these gases keeps the planet about $33^{\circ} \mathrm{C}$ warmer than it would be otherwise (Le Treut et al., 2007). This natural greenhouse effect, by providing protection from the loss of heat, has made most life on Earth possible. The functioning of the Carbon cycle has provided a good part of this protection; but human activities such as the combustion of fossil fuels, large-scale industrial pollution, deforestation and land-use changes, among others, have led to a build up of greenhouse gases in the atmosphere together with a reduction of the capacity of oceans and vegetation to absorb greenhouse gases.

This attack on natural carbon cycle on two fronts has reduced the Earth's natural ability to restore balance to the carbon Cycle and is now resulting directly in the current global changes in average temperatures. Looking back to the Earth's history, it is not surprising that its climate system has always changed (Ammann et al., 2007). Yet a remarkable stability is also evident, with variations in temperature within a narrow range over thousands of years before the industrial era (Sabine et al., 2004). Particularly striking about the current changes are the speed and intensity at which transformations in the greenhouse effect have been fostered by the exponential growth in concentrations of $\mathrm{CO}_{2}$ and other $\mathrm{GHG}_{\mathrm{s}}$ during the industrial era: the increase of about 100 parts per million since the dawn of industrialization has led to a dramatic alteration of both the Carbon Cycle and the climate system (Raupach et al; 2007).

An analysis of this period reveals that human actions are pushing the Earth's Climate beyond a tipping point where changes in human behaviour and systems will no longer be able to mitigate the effects of climate change as shown in table 1.

Table 1. Annual Atmospheric $\mathrm{CO}_{2}$ Data.

\begin{tabular}{|l|l|}
\hline Year & $\mathbf{C O}_{\mathbf{2}} \mathbf{( \mathbf { p p m } )}$ \\
\hline 1959 & 315.92 \\
\hline 1987 & 349.16 \\
\hline 1992 & 356.38 \\
\hline 1997 & 363.71 \\
\hline 2006 & 381.90 \\
\hline 2007 & 383.77 \\
\hline 2008 & 385.59 \\
\hline 2009 & 387.38 \\
\hline 2010 & 389.78 \\
\hline 2011 & 381.57 \\
\hline 2012 & 395.77 (June) \\
\hline
\end{tabular}

Source: NOAA-ESRL (Mauna Observatory) 2012. 
For the decade (2002-2011) the average annual increase is $2.07 \mathrm{ppm}$ per year. The average for the prior decade (1992-2001) is 1.6 ppm per year. The upper safety limit for atmospheric $\mathbf{C O}_{2}$ is 350 parts per million since early 1988. It is undeniable that the Earth's climate is warming. This is evident from models and observations at global and continental levels including the Fourth Assessment Report of IPCC, according to which there was an increase of $0.74^{\circ} \mathrm{C}$ during 1906 to 2005 (IPCC, 2007). It has been further validated by research published afterwards, according to which the observed increase in global mean surface temperature since 1990 is $0.33^{\circ} \mathrm{C}$ (Fussel, 2009).

\subsection{Urban Centers and Climate Change Links: A Conceptual Framework:}

Kates and Wilbanks (2003), viewed Earth's green house effect and its consequences as a dynamic causal chain between cities and climate change. To understand how urban centers generate greenhouse gas. It is necessary to find a representative measure of carbon emissions (Molina and Molina, 2002). Most of the total pollution comes from the combustion of fossil fuels (coal, oil and natural gas) for heat and electricity generation, for consumption by commercial and residential buildings, transportation and in industrial processes. Other sources are households consuming fuels in heaters and cookers, or indirectly in air conditioning. It is also usual to find carbon emissions resulting from land use changes and aggravated by poor land management and many paved roads. Landfill sites taking urban wastes are other key sources of methane. The manufacturing process used in the production of cement needed for the development of our urban areas can also account for as much as $5 \%$ of global emissions of greenhouses gases Finally, many other activities undertaken outside the boundaries of urban centers such as agriculture, and cattle rearing, aimed at satisfying urban requirements of food, raw materials, forest products and construction materials as well as electricity generation in rural areas but largely for urban use also contribute to carbon emission. Figure 1 illustrates the volume (in percentage) of emission by each sector.

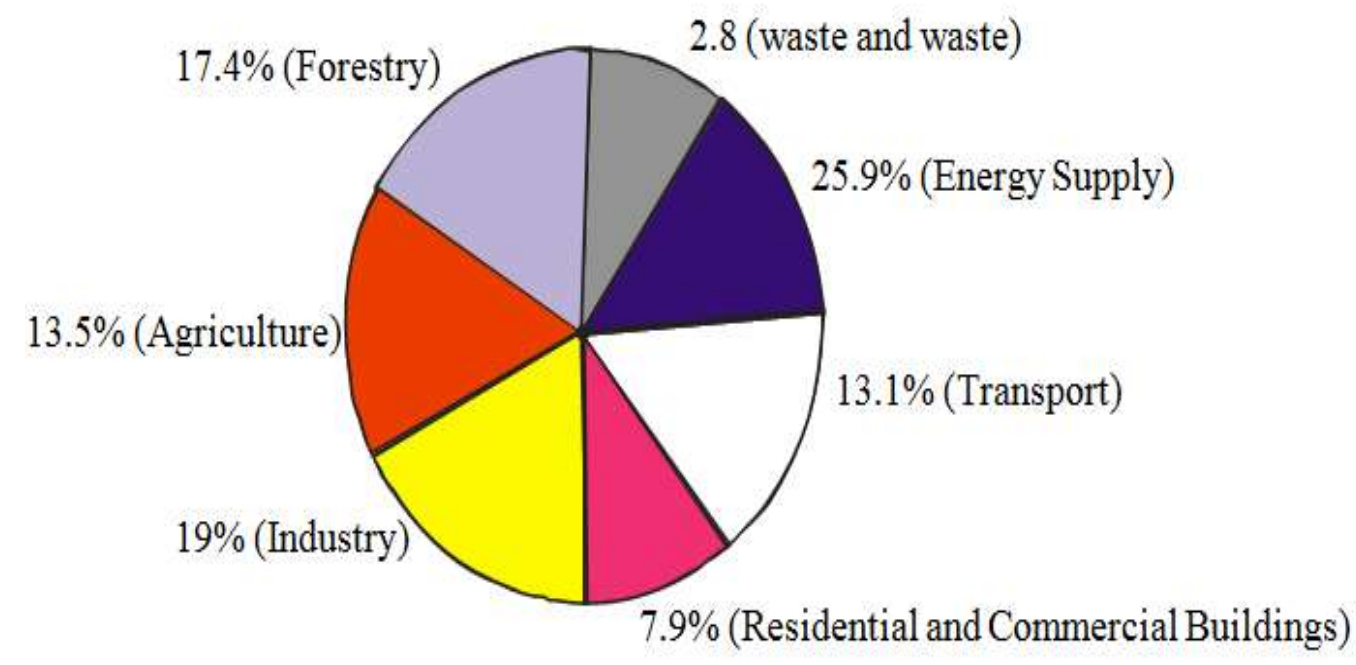

Source: IPCC, (2007b)

Figure 1: GHG emissions by sector in 2004

The main emitters is energy supply (25.9\%) followed by industry (19.4\%), forestry (17.4\%), agriculture (13.5\%) and transportation (13.1\%)- (IPCC,2007b). These greenhouse gases (GHGs), then, not only change the dynamics of the carbon cycle but also generate changes in the Earth's radiation budget that induce climates change. They create two main categories of impacts on the carbon Cycle and the climate system. Firstly, changes related to the emission of aerosols, greenhouse gases and solid wastes. Greenhouse gases are the main sources of changes in the climate system. They not only change the dynamics of the carbon cycle, but together with aerosols they also generate changes in the Earth's radiation that induce climate change (IPCC, 2007). Waste affects the growth, function and health of vegetation and of ecosystems in general (Alberte and Hufyra, 2009), which in turn affect the carbon cycle.

Secondly, land-use related changes. Urbanization is a process that changes the use of land and by creating impervious surface, filling wetlands, and fragmentation of ecosystems has disproportional impacts upon the carbon cycle. The built environment of urban areas is also a forcing function on the weather-climate system of urban centers because it is a source of heat and a poor storage system for water. The link between urban centers and climate change is diagrammatically shown in figure 2. Transportation, heating and cooling systems, industries, infrastructure act both as emitters and direct causes of climate change. 


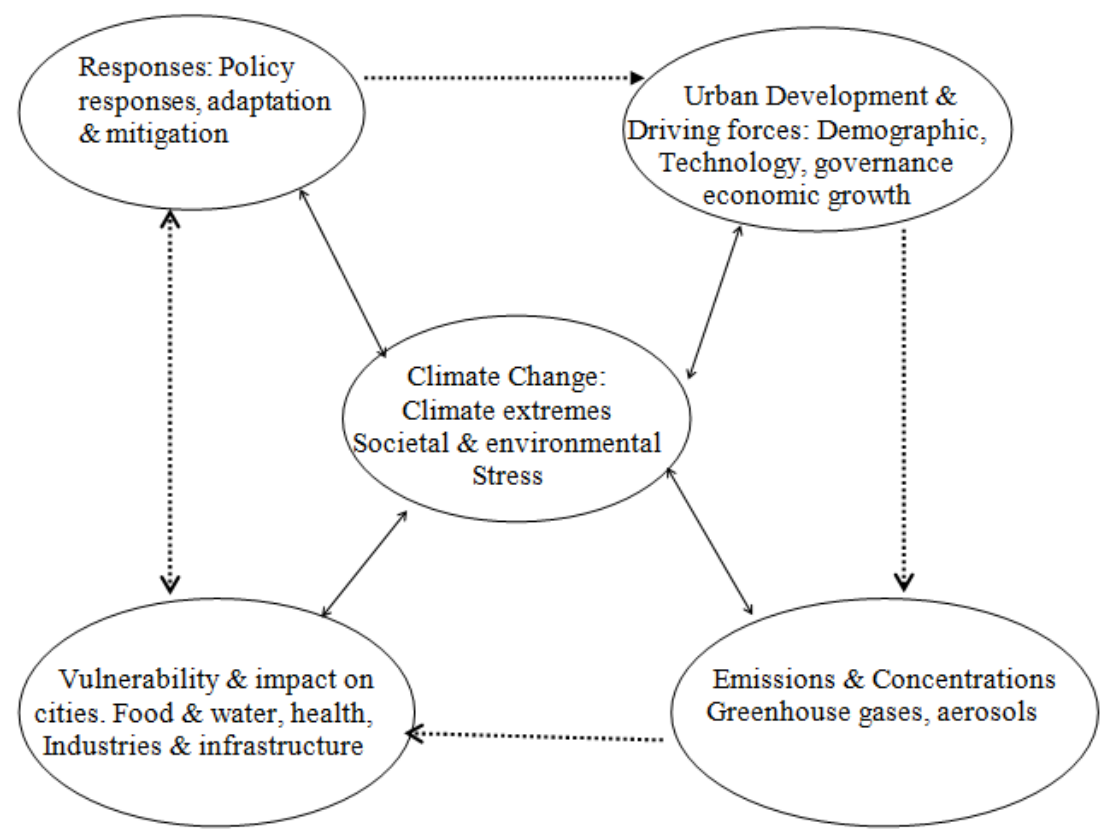

Figure 2: Urban Centers - Climate Change Link

\subsection{Why Nigeria Cities Are Vulnerable.}

Nigeria cities, like the rest of the entire continent of Africa, are considered highly vulnerable to climate change because of the following characteristics (IPCC, 1998):

- A high exposure and sensitivity to climate change

- Quite limited adaptive capacity in its current state of development

- Large proportions of the population are subject to other stresses such as poverty, illiteracy, food insecurity, malnutrition and disease, all of which could interact with climate change to further detract from wellbeing.

Nigeria cities are vulnerable to present-day climatic variability in the form of extreme climatic events that include sea-level rise, storm surges, flooding, inundation and drought. According to Nwafor, (2006), factors likely to exacerbate the vulnerability of Nigeria cities to climate impacts comprise:

- Location in the tropical climate region where impact is likely to be severe

- High population growth rate

- Rapid urban expansion that is exerting pressure on physical infrastructure

- Accompanying congestion in insalubrious living conditions

- Wide-spread and deepening poverty, inequity and lack of social justice

- Large unmet demand for power, telecommunications, transport and water

- Unsustainable industrial practices

- Excessive concentration of urban settlements, industry (oil and gas), port facilities and other investments in the coastal zone; and

- Excessively high levels of pollution in the coastal zone.

\subsection{Climate Change: Implication for urban centers.}

Climate change has a variety of potential implications for urban areas, some of which have already been pointed out by scholars like (Bigio, 2003; Wilbanks and Romero et al., 2007; Stterthwaaite et al., 2007; Hunt and Watkiss, 2007).Climate change may influence almost all components of the urban environment, and raise new, complex challenges to the quality of urban life, health and urban biodiversity. Increases in flooding or temperatures may result not only in deaths, but also in water-borne diseases outbreaks and increased stress, and may affect mental health (Reacher et al., 2004; Ahern et al., 2005).According to IPCC (2007a) runoff and water availability are projected to have regional differentiated behaviour by 2050 . Increases in the frequency and severity of floods and droughts as well as declines in water qualities stored in glaciers and snow cover are also expected. All these changes will have profound consequences for cities in terms of both water resources and water systems.

Many water basins will get less precipitation constraining the availability of freshwater sources for urban centers. These will be especially hard for growing cities and large cities that already face serious problems to obtain sufficient freshwater supplies. Example, urban centers along Bornu, Sokoto, Yobe axis. Climate variability and change affects urban water supply and sewage systems in different ways (Wilbanks and Romero 
Lankao et al., 2007). Increased temperatures can affect water demand for drinking, for cooling systems and for garden watering (Enete and Ezenwaji, 2011). Urban water supplies can be reduced through changes in precipitation patterns, reductions in river flows, failing ground water tables and in coastal areas, saline intrusion in rivers and ground water. This will mean substantial impacts on water flow and by extension, reductions in hydro electric generation (Magrin and Gay et al., 2007; Vergara, 2005).

Urban ecosystems will be affected by changes like changes in the wind flow, temperature, humidity and precipitation and may alter patterns of vector-borne diseases. Urban flora composition and with it, the fauna, in the face of climate change, continues to show a high dynamic of change and adaptation developments. (BFN.2009).Continuing urbanization is projected to further alter biodiversity due to the loss of habitats and green spaces in densely populated inner-city areas and urban sprawls in the wider country side, if not balanced by appropriate urban and landscape planning (EEA, 2010e; EEA, $2010 \mathrm{k}$ ). Also, green urban areas and species could suffer from climate changes such as temperature and precipitation and could no longer provide ecosystem services.

Health effects related to the limited availability and quality of drinking water and increases in episodes of food poisoning cannot be ruled out (Costello et al., 2009; RCEP, 2007). Furthermore, climate change may exacerbate existing environmental problems including those related to air pollution due to increased particulate matter and ground level Ozone concentrations, flooding and water supply problems. As a feedback loop, climate change can influence people's consumption, for example, energy demand for cooling and heating, or irrigation of urban green spaces; that could cause further environmental burdens. WHO (2009b), emphasized that the combined effects of temperature and air pollution could lead to further increased mortality on hot days when the population is exposed to high concentration of $\mathrm{PM}_{10}$ and ozone.

The strength of the relationship between daily outdoor temperature and health outcomes differ between countries, between cities and even in the same Location from one year to the next (WHO, 2009a; Baccini et al., 2008). Observed differences among cities and between regions could also reflect demographic, cultural, socioeconomic and technological status (Baccini et al., 2008).

Local conditions and urban design can aggravate climate effects. High soil sealing can aggravate the urban heat Island effect and increased further temperatures in the city. One important characteristic of the 2007 flooding events in United Kingdom was that a high proportion of overland flooding was trapped in areas with poor drainage (Pitt, 2008). The same observation was made in flooding that claimed many life's in Ibadan in 2011 and Jos in 2012. The urban centers that are more at risk are those where the events in table 2 are already widespread.

Table2: climate change impacts on urban centers

\begin{tabular}{|l|l|}
\hline Climate phenomena & Major projected impacts \\
\hline $\begin{array}{l}\text { Warier and more frequent hot days } \\
\text { and night }\end{array}$ & $\begin{array}{l}\text { Increased demand for cooling. Declining air quality in } \\
\text { cities. } \\
\text { Increased disruption to transport due to overheating of } \\
\text { engines. }\end{array}$ \\
\hline Warn spells/heat waves & $\begin{array}{l}\text { Reduction in quality of life for people in warm areas } \\
\text { without air conditioning. Impacts on elderly, very young, } \\
\text { the sick and poor. }\end{array}$ \\
\hline Heavy precipitation events & $\begin{array}{l}\text { Disruption of settlements, Commerce, transport and } \\
\text { societies due to flooding. Pressure on infrastructure, } \\
\text { potentials for use of rain in hydro power generation. }\end{array}$ \\
\hline Cities affected by drought & $\begin{array}{l}\text { Water shortages for households, industries and services. } \\
\text { Reduced hydro power generation potentials. Potentials for } \\
\text { population migration. }\end{array}$ \\
\hline High sea rise & $\begin{array}{l}\text { Costs of coastal protection versus costs of land- use } \\
\text { relocation. Decreased freshwater availability due for } \\
\text { movement of population and infrastructure. }\end{array}$ \\
\hline
\end{tabular}

Source: IPCC (2007a)

\subsection{Conclusion}

This paper has examined the relationship between urban centers and climate change. They are sources of both developmental and environmental challenges and opportunities. Urbanization is a major component of rapid economic growth that has contributed to improvement in the quality of life of urban population. There is also a complicated series of interactions between urban centers and climate change. Urban centers are zones of job creation, policy formulation, opportunities as well as emitters of greenhouse gases that trigger climate change. The impacts of global GHG emissions currently manifest in stronger and more frequent floods, 
droughts, heat waves adversely affecting industries, and populations of urban centers. As a result, urban centers and their economic sectors are faced with challenges: the need to adapt, at least to some amount of warming, and the urgency to mitigate the causes of global climate change.

\section{References}

[1] Ahern, M. Kovats, S. Wilkinson, P. Few, R. Matthies, F (2005). 'Global Health Impact of Floods: Epidemiologic Evidence "Epidemiology Review 27:36-46.

[2] Awosika, L.F. (1992). Coastal Erosion in West African: Causes, Effects and Responses Options. Paper presented at International Convention on Rational use of the Coastal zone. Bordeaux, France.

[3] Baccini, M. Biggeri, A. Accetta, G. Kosatsky, T. Kasouyanni, K Analitis, A Ross Anderson, H. Biasanti, L.D. Ippoliti, D. Danova, JForsbery, B. Medina, S. Paldy, A. Rabczenko, D. Schindler, C. Michelozzi, P. (2008). Effects of apparent temperature on Summer Mortality in 15 European Cities: results of the PHENE project Epidemiology 19(5)

[4] BFN, (2009). Biological Diversity in Cities - A Review and Bibliography. BFN-Skrichten 245/2009. Bonn-Bad Godseberry Bondurant fur Naturschutz

[5] Bigio, A (2003). "Cities and Climate Change", in: Building safe cities. The future of Disaster risk, (Kreimer; A. Arnold, M and Karlin, A (eds) World Bank (global settlements).

[6] Costello, A. Abbas, M. Allen, A. (2009). Managing the Health Effects of Climate Change. The Lancent Commission. Lancet and university College London Institute for Global Health Commission. The Lancet. Vol. 373(16).

[7] Dodman, D. (2009). Blaming cities for climate change? An Analysis of Urban Greenhouse Gas Emissions Inventories. Environment and Urbanization, 21(1): 85-201

[8] EEA (2010e). The European Environment- State and Outlook 2010: Land use. European Environment Agency, Copenhagen.

[9] EEA (2010k). The European Environment- state and Outlook 2010: biodiversity. European Environment Agency, Copenhagen

[10] Entete, I C and Ezenwaji, E.E (2011). Implications of climate Variability on Water resource of Nigeria A review. Journal of Geography and Regional Planning Vol. 4(13): 678-682.

[11] Hughes, R.H. and Hughes, J.S (1992). A Directory of African Wetland. Gland Switzerland and Cambridge, IUCN, UK; UNEP, Nairobi, Cambridge; UK; WMCM.

[12] Hunt, A and Watkiss, P. (2007). Literature Review on Climate Change Impacts on Urban City Centers; Initial findings. ENV/EPOC/GSP (2007) 10. Paris, France: OECD.

[13] IPCC, (2007a) Climate Change 2007: Impacts, Adaptation and Vulnerability Summary for policy Makers, Geneva, Switzerland.

[14] IPCC (2007b). Climate change 2007: Mitigation of Climate change. Contribution of working Group III the fourth Assessment Report of the Intergovernmental Panel on Climate change (B. Metz, O. R. Davidson, P.R. Bosch, R. Dave, L.A Meyer (eds.) Cambridge University Press, Cambridge, United Kingdom and New York, NY, USA, p. 851.

[15] IPPC (1991). Climate change: The IPCC Responses Strategies. Island Press, Washington, D.C.

[16] IPCC (1998).Regional Impacts of Climate Change: An Assessment of Vulnerability. A Special Report of IPCC Working Group II Published for the IPCC by Cambridge University Press, Cambridge.

[17] Kates, S and Wilbanks, T (2003). Making the Global local: Responding to Climate change Concerns from the Bottom up. Environment, 45(3):12-23.

[18] Margin, G. Gay, C. Cruzy Choques, D. Jimenez, J.C. Moreno, A.R. Nagy, G. Nobre, C. Villamizar, A. (2007),” Chapter 13- Latin America" IPCC WGII Fourth Assessment Report, p.63.

[19] Molina, L.T and Molina, M. J (eds.)(2002). Air quality in the Mexico Mega City. An integrated assessment. Netherlands: Kluwer Academic Publishers.

[20] Nwafor, J.C (2006). Environmental Impact Assessment for Sustainable Development: The Nigeria Perspective. Environment and Development Policy Centre for Africa (EDPCA), Enugu.

[21] Pitt, T (2008). Learning lessons from the 2007 floods. The Pitt Review. Cabinet Office, 22 Whitehall, London SWIA 2WH. http://archive. Cabinet office. gov. uk /pittreview/the pittreview/final-report.html(accessed 24/7/12).

[22] RCEP(2007). The Urban Environmet. Royal Commission on Environmental pollution. www.rcep.org.uk/reports/26 urban/documents/urban-environment. Pdf (accessed 24/7/12).

[23] Reacher, M. Mckenzie, K. Lane, C. (2004). Health Impacts of Flooding in Lewes: A comparison of reported gastrointestinal and other illness and mental health in flooded and non flooded households. Commun Dis Oublic Health. 7:56-63.

[24] Satterthwaite, D. Hug, S. Pelling, M. Reis, A and Romero- Lankao, P. (2007). Building Climate Change Resilience in Urban Areas and Among Urban populations in Low- and Middle income Countries, commissioned by the Rockefeller Foundation, International Institute for Environment and Development (RIIED) research Report, 112.

[25] United Nations (2010). World Urbanization Prospects. 2099 Revision. New York: UN Department of Social and Economic Affairs.

[26] Vergara, W (2005). Adapting to Climate Change. Lessons Learnt, Work in Progress and Proposed next steps for the World Bank in Latin America, World Bank, LCR. Environmentally and sustainable Development Department working paper No. 25 , pp 55.

[27] WHO (2009a). Night Noise Guidelines for Europe. WHO Regional Office for Europe, Copenhagen. www.euro.who.int/data/assets/pdf-file/0017/43316/E92845.pdf(accessed 24/7/12).

[28] WHO (2009b). Improving Public Health Responses to Extreme Weather/heat waves-Europ Heat. WHO Regional Office forEurope,Copenhagen.www.euro.who.int/data/assets/pdffile/0010/95914/E92474.pdf(accessed 24/7/12).

[29] Willbanks, T. Romero Lankao; P. Bao, M. Bork out, F. Cairncross, S. Ceron, J. P. Kaphse, M. Muirwood, R Zapate-marti; R. (2007). "Industry, settlement and society, in parry, in: Canziani, O. Palutikof, F. Vander linden, P. Hanson, C (eds) climate change 2007. Impacts, Adaptation and vulnerable (2007) Climate change 2007: Synthesis Report. Contribution of Working Groups, I,II and III to the Fourth Assessment Report of the Intergovernmental Panel on Climate Change (core writing Team, Pachauri; R.K and Reisinger, A (eds.)\}. IPCC, Geneva, Switzerland, p. 104.

[30] World Bank (2009). World Development Report: Reshaping Economic Geography. Washington, DC: World Bank. 